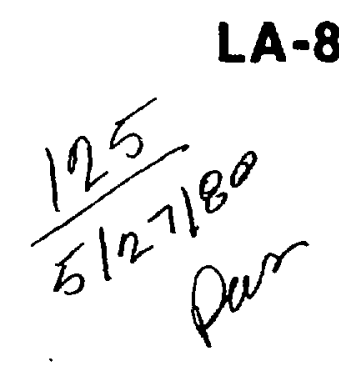

DR. 1225

\title{
Low-Energy Nuclear Fusion Data and \\ Their Relation to Magnetic and Laser Fusion
}

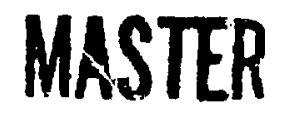

足 


\title{
Low-Energy Nuclear Fusion Data and
}

\section{Their Relation to Magnetic and L.aser Fusion}

\author{
Nelson Jarmie
}
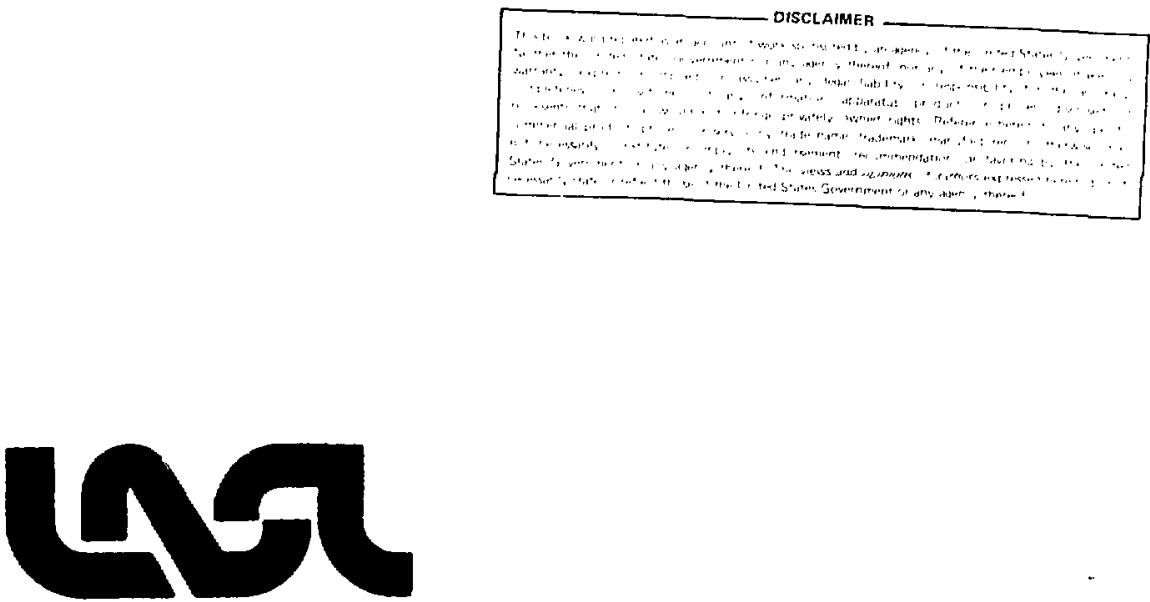


\title{
LOW-ENERGY NUCLEAR FUSION DATA AND THEIR RELATION TO MAGNETIC AND LASER FUSION
}

by

\author{
Nelson Jarmie
}

\begin{abstract}
We investigated the accuracy of the basic fusion data for the $T(d, n)^{4} \mathrm{He}$, ${ }^{3} \mathrm{He}(\mathrm{d}, \mathrm{p})^{4} \mathrm{He}, \mathrm{T}(\mathrm{t}, 2 \mathrm{n})^{4} \mathrm{He}, \mathrm{D}(\mathrm{d}, \mathrm{n})^{3} \mathrm{He}$, and $\mathrm{D}(\mathrm{d}, \mathrm{p}) \mathrm{T}$ reactions in the $10-$ to $100-\mathrm{keV}$ bombarding energy region, and assessed the effects of inaccuracies on the design of fusion reactors. The data base for these reactions /particularly the most critical $\mathrm{T}(\mathrm{d}, \mathrm{n})^{4} \mathrm{He}$ reaction] rests on 25 -year-old experiments whose accuracy (often assumed to be $\pm 5 \%$ ) has rarely been questioned: yet in all except the $d+d$ reactions, there are significant differences among data set:- The errors in the basic data sets may be considerably larger than previously expected. and the effect on design calculations should be significant. Much of the trouble apparently lies in the accuracy of the energy measurements, which are dificult at low energies. Systematic error s of up to $50 \%$ are possible in the reactivity values 'f the present $\mathrm{T}(\mathrm{d}, \mathrm{n})^{4} \mathrm{He}$ data base. The errors in the reactivity will propagate proportionately into the errors in fusion probabilities in reactor calculations. ${ }^{3} \mathrm{He}(\mathrm{d}, \mathrm{p})^{4} \mathrm{He}$ reaction cross sections could be in error by as much as $50 \%$ in the low-energy region. The $D(d, n)^{3} \mathrm{He}$ and $D(d, p) T$ cross sections appear to be well known and consistent. The $T(t, 2 n)^{4} \mathrm{He}$ cross section is poorly known and may be subject to large systematic errors. Improved absolute measurements for all the reactions in the low bombarding energy region ( 10 to $100 \mathrm{keV}$ ) are needec:. 'sut until they are done, the data sets should be left as they are lexcept for $T(t, 2 n)^{6} \mathrm{He}$ data, which could be lowered by absut 50\%\}. The apparent uncertainties of these data sets should be kept in mind.
\end{abstract}

\section{INTRODUCTION}

We investigated the accuracy of the basic fusion data for the reactions $\mathrm{T}(\mathrm{d}, \mathrm{n})^{4} \mathrm{He},{ }^{3} \mathrm{He}(\mathrm{d}, \mathrm{p})^{4} \mathrm{He}, \mathrm{T}(\mathrm{t}, 2 \mathrm{n})^{4} \mathrm{He}$. $D(d, n)^{3} \mathrm{He}$, and $D(d, p) T$, and assessed the effects of errors on magnetic or inertial fusion reactor design. The data base for these reactions, particularly the most critical $T(d, n)^{4}$ He reaction, was taken from 25 -year-old experiments whose accuracy (often assumed to be $\pm 5 \%)$ has rarely been questioned. As reactor experiments and design become more sophisticated, various discrepancies stand out, and we must understand the influence of these uncertainties in the basic fusion data. We show that errors in the basic data sets may be considerably larger than have been accepted, and that the effects on design calculations should be significant. This conclusion will provide motivation for improved experiments.

Our emphasis will be on the $T(d, n)^{4} \mathrm{He}$ reaction. ${ }^{3} \mathrm{He}(\mathrm{d} . \mathrm{p})^{4} \mathrm{He}$ was studied not only for its own sake, but because the same equipment was often used to measure T(d.n'ilike. Section II describes the data sources that are 
used in fusion calculations. Section III indicates the sensitivity of reactor design calculations to uncertainties in the basic data. In Sec. IV, we discuss the evidence for the larger-than-expected uncertainties in the 10- to 100$k e V$ bombarding energy region. Section $V$ summarizes the conclusions.

The energy region of interest is from 10 to $120 \mathrm{keV}$ bombarding energy. This corresponds to a temperature (assuming a triton beam) of an interacting $D+T$ plasma of from 0.5 to $20 \mathrm{keV}$ (Sec. III). This temperature scale is the result of folding the Maxwell velocity distributions in the plasma with the cross section and from a laboratory to center-of-mass (c.m.) conversion.

To assess the energy region of interest for planning an eventual fusion reactor, we show a graph of the Lawson criterion $^{2}$ (Fig. 1), which indicates conditions necessary for "breakeven" in a burning $\mathrm{D}+\mathrm{T}$ plasma. The optim n plasma temperature for the lowest nt is $\sim 20$ to $30 \mathrm{keV}$ temperature. Early reactors probably will operate on the lower side of this minimum, say, from 1 to $30 \mathrm{keV}$, which corresponds to a laboratory bombarding energy in our range of interest.

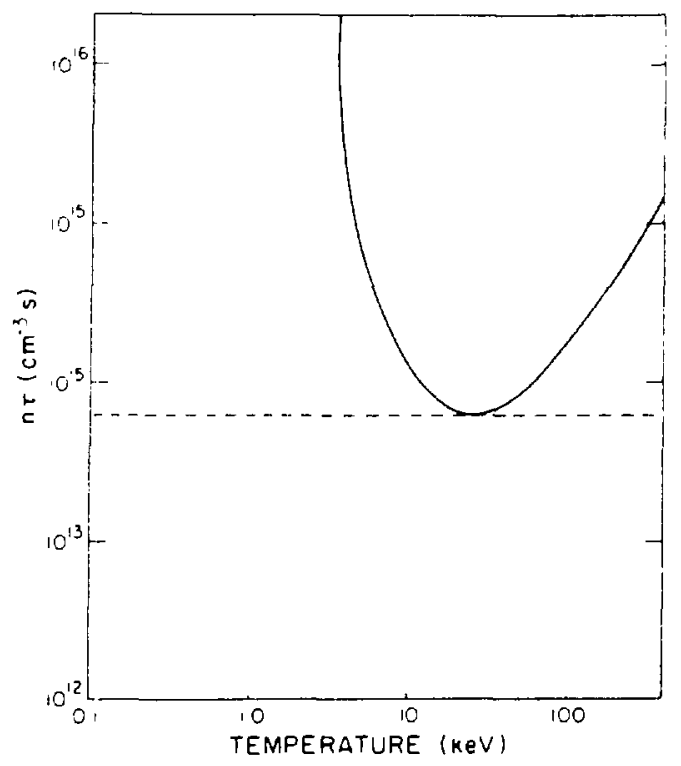

Fig. 1.

Lawson criterion for minimum product of density and burning time to produce net energy balance against plasma energy losses vs plasma temperature.
A study of the relation of the accuracy of the basic fusion data on the design of nuclear weapons has been published. $^{3}$

\section{DATA SOURCES}

\section{A. $\mathbf{T}(d, n)^{4} \mathrm{He}$}

The total cross section is shown in Fig. 2. The reactivity is plotted against temperature in keV in Fig. 3. The shape is dominated by a nuclear resonance near $100 \mathrm{keV}$ bombarding energy and by the typical exponential Gamow penetration at lower energies.

The $T(d, n)$ low-energy data came from three main references. Arnold et al. ${ }^{4}$ at Los Alamos measured $\sigma\left(90^{\circ}\right)$ down to $\sim 10 \mathrm{keV}$ (laboratory bombarding energy), claiming $2 \%$ accuracy. (Because the reaction is isotropic in the c.m. system below several-hundred keV, the $\sigma\left(90^{\circ}\right)$ is easily converted to an integrated cross section $\sigma_{\mathrm{T}}$.) Conner, Bonner, and Smith ${ }^{5}$ at Rice University measured $\sigma\left(90^{\circ}\right)$ down to $10 \mathrm{keV}$ with $3 \%$ accuracy, and Katsaurov ${ }^{6}$ at the Lebedev Institute measured $\sigma_{\mathbf{T}}$ down to $45 \mathrm{keV}$ claiming 2-3\% accuracy. Earlier experiments, like those of Jarvis and Roaf" in

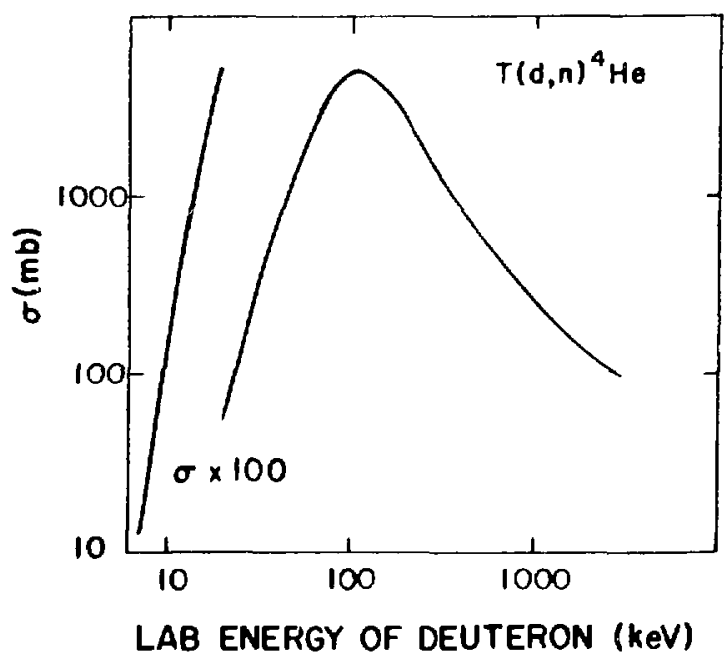

Fig. 2.

Total reaction cross section for $T(d, n)^{4} \mathrm{He}$ as a function of laboratory deuteron energy. The cross section is dominated by a narrow nuclear resonance in the compound ${ }^{6} \mathrm{He}$ system, which is manifest at about $107 \mathrm{keV}$ deuteron energy. 


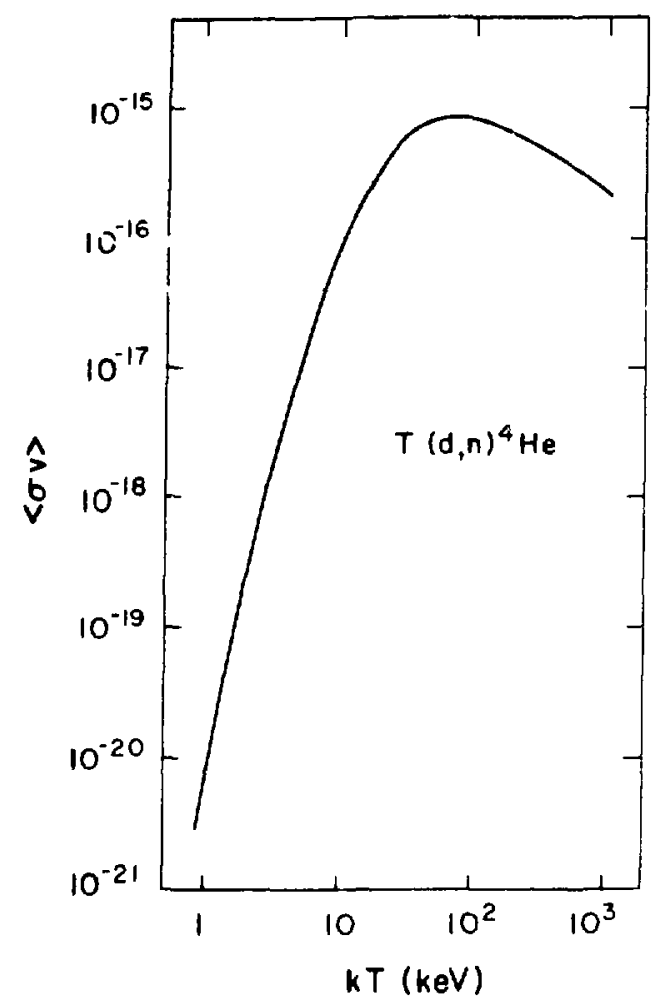

Fig. 3.

The reactivity of $T(d, n)^{4} \mathrm{He}$ vs temperature. The reaction cross section in Fig. 1 is used to compute the mean of $\langle\sigma v\rangle$ where $v$ is the relative velocity of the deuteron and triton, and both particles are assumed to have Maxwell distributions of temperature $T$. The units of $\langle\sigma v\rangle$ are $\mathrm{cm}^{3} / \mathrm{s}$.

England (20-40 keV, about 10\% accuracy), disagreed with the later U.S. experiments and were seldom used.

Most data bases in fusion reactor calculations have come, eventually, from the work of Arnold ${ }^{4}$ and ronner, ${ }^{5}$ sometimes circuitousiy. In general, LASL's Magnetic Fusion Energy Program uses a standard data set, $^{8}$ based on an ORNL (Oak Ridge National Laboratory) table, ${ }^{9}$ which is part of the Magnetic Fusion Energy Computer Network. In turn, the ORNL table is based on compilations by Greene ${ }^{10}$ and Tuck, ${ }^{11}$ both of which are drawn from Refs. 4 and 5. Computational representations of the $T(d, n)$ reactivities by Hively'12 and Miley'13 are based on Duane's compilation, ${ }^{14}$ again, drawn from the data of Arnold et al. ${ }^{4}$ and Conner.'

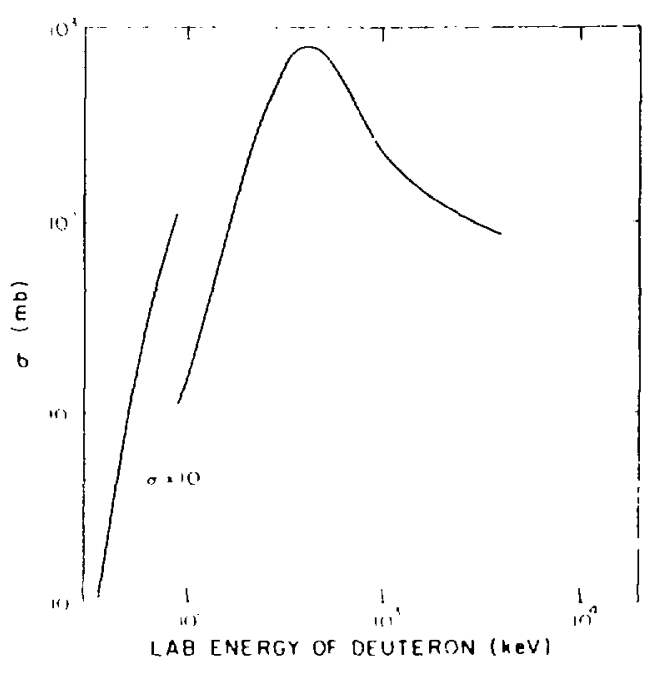

Fig. 4.

Total reaction cross section for ${ }^{3} \mathrm{He}(d, p)^{4} \mathrm{He}$ as a function of laboratory deuteron energy. It is similar to that of iis mirror reaction in Fig. 2, except the nuclear resonance is at about $430 \mathrm{keV}$.

A parameterization of the $\mathrm{T}(\mathrm{d}, n)^{4} \mathrm{He}$ reaction by Artsimovich ${ }^{13}$ is sometimes used. The data base is not known and the parameterization disagrees markedly with experiments ncar the resonance (see Ref. 17).

Calculations for the Laser Fusion program are dominated by a large hydrodynamics program, ${ }^{16}$ whose data set for the reactions being studied stems from Greene's work, ${ }^{10}$ and thus to Arnold ${ }^{4}$ and Conner. ${ }^{5}$ None of these data bases includes Katsaurov's data. ${ }^{6}$

Stewart and Hale ${ }^{17}$ describe an R-matrix analysis of the mass-5 system, which gives an improved prediction for the $T(\mathrm{~d}, n)^{4} \mathrm{He}$ reaction from $5 \mathrm{keV}$ to $1 \mathrm{MeV}$. So far as we know, this analysis is not included in any of the fusion data sets. The Katsaurov data ${ }^{6}$ were also excluded from the R-matrix analysis.

\section{B. ${ }^{3} \mathrm{He}(\mathrm{d}, \mathrm{p}){ }^{4} \mathrm{He}$}

The trend of the data is shown in Fig. 4. The corresponding nuclear resonance is shifted by Coulomb effects to much higher energies than in the $T(d, n)^{4} \mathrm{He}$ reaction.

Again, the data bases in all fusion work for this reaction use Greene's compilation. ${ }^{10}$ Below $1 \mathrm{MeV}$ bombarding energy, Greene draws mainly from Arnold et 
a!." (who measure $\sigma_{\mathrm{T}}, 36-93 \mathrm{keV}, 2.6 \%$ ); Jarvis and Roaf $^{\mathcal{T}}\left(\sigma_{\mathrm{T}}, 29-43 \mathrm{keV}, 6-14 \%\right)$; Bonner, Conner, and Lillie $^{18}\left(\sigma_{\mathrm{T}}, 188-1597 \mathrm{keV}, 3 \%\right)$; Kunz ${ }^{19}\left(\sigma_{\mathrm{T}}, 66-530\right.$ $\mathrm{keV}, 10 \%)$; Freier and Holmgren ${ }^{20}\left(\sigma_{\mathrm{T}}, 360-550 \mathrm{keV}\right.$, $8 \%)$; and Yarnell, Lovberg, and Stratton ${ }^{21}\left(\sigma_{\mathrm{T}}, 260\right.$ $3560 \mathrm{keV}, 5 \%$ ). Data on this reaction also exist in unpublished theses by Carlton ${ }^{22}$ and Dwarakanath, ${ }^{23}$ and in early work by Kliucharev, Esel'son, and Valter. ${ }^{24}$

\section{C. $\mathrm{T}(t, 2 n)^{4} \mathrm{He}$}

Greene's compilation ${ }^{10}$ is also the source of data for the design codes. His work depends largely on Govorov et al.. ${ }^{29}$ who measure $\sigma_{\tau}$ from $60-1140 \mathrm{keV}$ (5\% accuracy). He excludes the data of Agnew et al. ${ }^{26}$ (down to $40 \mathrm{keV}$, o $\left(90^{\circ}\right), 4 \%$ accuracy]. Experiments done since Greene' $\mathrm{s}^{10}$ compilation include Strel'njkov et al., ${ }^{27}$ who measure $\sigma\left(90^{\circ}\right)$ from $40-200 \mathrm{keV}$ (15\% uncertainty claimed), and Serov, Abramovich, and Morkin, ${ }^{28}$ who measure $\sigma\left(0^{\circ}\right)$ and $\sigma_{\mathrm{T}}$ from 30-160 keV. Serov's numerical data are also available. ${ }^{29}$ For completeness, we include measurements of $\sigma\left(90^{\circ}\right)$ from $230-1000$ $\mathrm{keV}$ by Govorov et al., ${ }^{30}$ and measurements of the neutron and alpha spectra by Bame and Leland," Wong, Anderson, and McClure, ${ }^{32}$ Larose-Poutissou and Jeremie, ${ }^{33}$ and Jarmie and Allen. ${ }^{34}$

\section{D. $D(d, n)^{3} H e$ and $D(d, p) T$}

Many experiments measuring 2bsolute cross sections $^{39-49}$ were done partly because of a report of a narrow resonance near $E_{d}=100 \mathrm{keV}$ and the comparison of the two branches. Unlike the $T(d, n)$ and $T(t, 2 n)$ reactions, the angular distribution is highly anisotropic at low energies. The shape of the total cross sections is shown in Fig. 5. A good summary of the experiments is given by Theus. ${ }^{35}$ At lower energies, Greene $^{10}$. uses data from Refs. $4,37,38$, and 40.

\section{SENSITIVITY OF FUSION REACTION RATE TO CROSS-SECTION ERROR}

The reaction rate $\mathbf{R}$ in a reacting plasma is proportional to $\langle\sigma v\rangle$, which in turn, is proportional to a folding of the Maxwell-Boltzmann distribution of

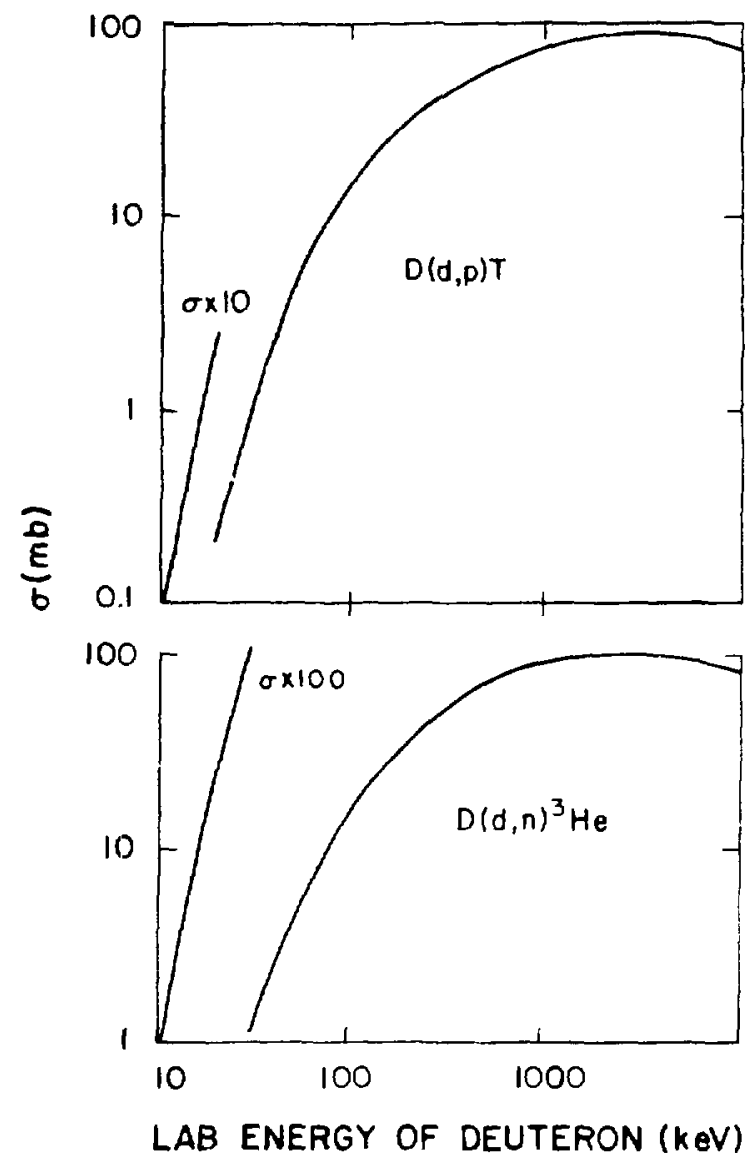

Fig. 5.

Total reaction cross sections for the bombardment of deutei uns by deuterons.

relative energies $E$ with the nuclear cross section $\sigma(E)$, so tha:

$R=C(k T)^{-3 / 2} \int \sigma(E) E \exp (-I / k \Gamma) d E$

where $C$ is a known constant ${ }^{1}$ and $T$ is the plasma temperature. Equation (1) shows that if the errors in the cross section are a function of energy, the effect on the accuracy of the reaction rate may be complicated. This problem is addressed by Santoro and Barish, ${ }^{\text {,6 }}$ who calculate the cross-section sensitivity of the fusion reaction rate for various conditions. Figure 6 is an example 


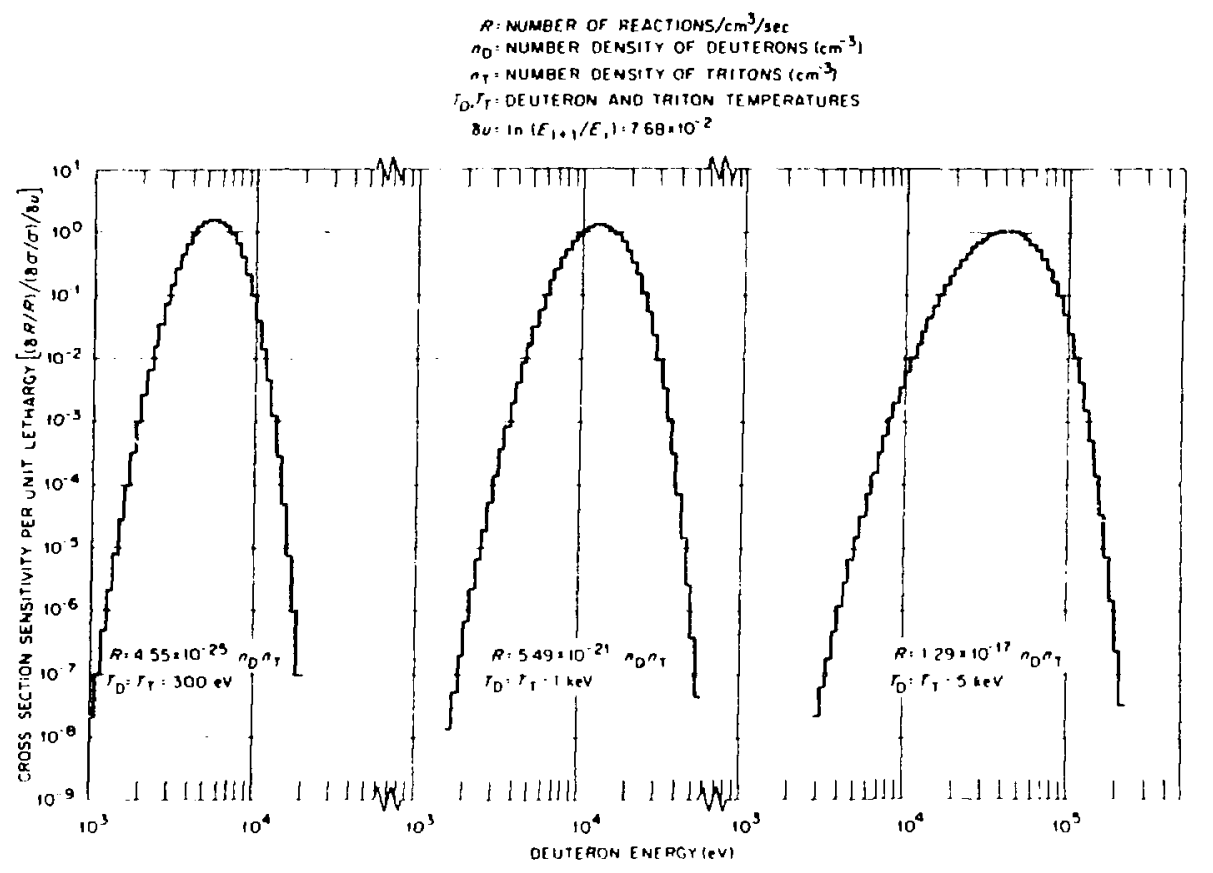

Fig. 6.

Cross-section sensitivity per unit lethargy of the $T(d, n)$ reaction raie us laboratory deuteron energv for ' $\dot{y}+$ T plasma (Sec. 11I). This graph is taken fium Ref. 46 (ORNL-DWG 75-5552).

of their results, where we plot the fractional error in the seaction rate per unit fractional error in the cross section per unit lethargy. Lethargy is an energy variable $\mid \mathrm{u}$ $=\ln \left(E_{\mathrm{o}} / E_{1}\right) \mid$, where $E_{0}$ is a standard energy; it is used so that the histogram intervals remain constant on a log$\log$ graph. Thus, if we know the cross-section error for each interval, we can estimate the reaction rate error. If the fractional error in the cross section is constant, then it can be shown that this error propagates proportionately to the fractional error in the reaction rate, as one might intuitively expect.

The function in Fig. 6 is directly related to the in tegrand of Eq. (1), and again shows the energy region of interest and the energy range in which the cross-section errors are significant.

\section{DISCREPANCIES AND UNCERTAINTIES IN EXPERIMENTAL DATA}

\section{A. $\mathrm{T}(\mathrm{d}, \mathrm{n})^{4} \mathrm{He}$}

Evidence for a systematic discrepancy in the $T(d, n)$ cruss-section data comes from (1) discrepancies in the basic data, and (2) discrepancies for different reactions in data taken with the same physical equipment, primarily ${ }^{3} \mathrm{He}(\mathrm{d}, \mathrm{p}){ }^{4} \mathrm{He}$ and ${ }^{6} \mathrm{Li}\left(\mathrm{p},{ }^{3} \mathrm{He}\right){ }^{4} \mathrm{He}$.

Stewart and $\mathrm{Hale}^{17}$ discardef Katsaurov's data $^{6}$ because of an apparent energy shift in the Russian data. However, details of Katsaurov's work indicate that it was carefully controlled with due regard for the difficulty of measuring such a low energy. It is not clear in whose work the energy discrepancy lies. Figure 7, taken from Stewart and Haie. ${ }^{17}$ illustrates the situation. The line in the figure is the R-matrix fit that agrees with standard U.S. data. ${ }^{4.5}$ The circles (Katsaurov data) are shifted to lower energies by about $6 \mathrm{keV}$, leading to a crosssection discrepancy (standard values low) of $10-30 \%$ in the low-energy region. Figure 8 shows the low-energy detail. Also included is a point by Jarvis and Roaf, ${ }^{7}$ which, if correct, agrees with Katsaurov's energy scale. ${ }^{6}$ (The Jarvis and Roaf data ${ }^{7}$ also were not included in the Stewart and Hale report.)

Accurate measurement of the bombarding energy is difficult at low energies, and this is suspected to be the main cause of the cross-section discrepancies. Because the cross sion is falling in a steep cxponential, slight 


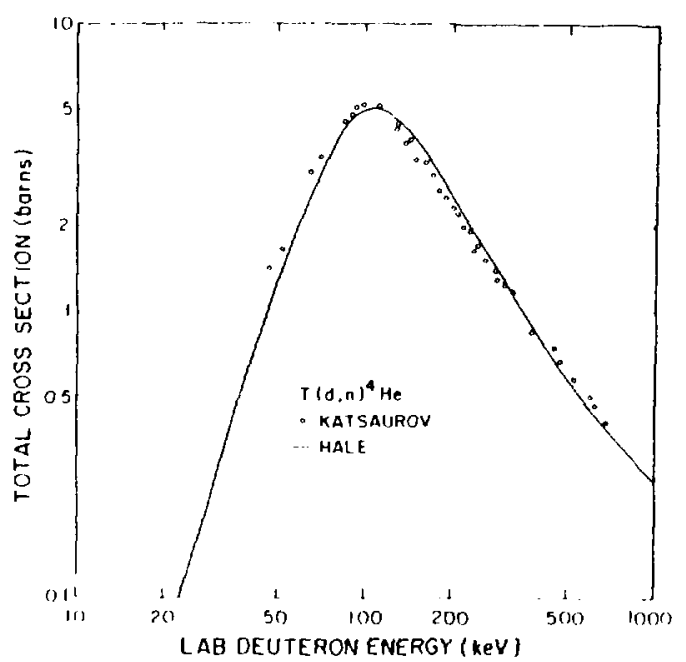

Fig. 7.

Detail of the $T(d, n)^{4} H e$ tolal cross section showing the experimental data. The line is an $R$-mairix fit" to known data other than those of Katsaurov. ${ }^{6}$ Note the apparent energy shift between the Katsaurov values ${ }^{6}$ and those from other data.

energy shifts can produce a large error in the crosssection magnitude. Using the cross-section parameterization as a function of energy from Refs. 15 and 17 , one can calculate, for example, that at $20 \mathrm{keV}$, a shift $\mathrm{dE}$ of only $0.5 \mathrm{keV}$ in the bombarding energy will produce a $10 \%$ change in the cross section. At the lower energies. the fractional cross-section error varies as $\mathrm{dE} / \mathrm{E}^{3 / 2}$, so that the effect increases as the energy decreases.

\section{B. ${ }^{3} \mathrm{He}(\mathrm{d}, \mathrm{p})^{4} \mathrm{He}$ and ${ }^{6} \mathrm{Li}\left(\mathrm{p},{ }^{3} \mathrm{He}\right)^{4} \mathrm{He}$}

The main "J.S. groups (Bonner, Conner, and Lillie," and Arnold et al. ${ }^{4}$ ) also measured the ${ }^{3} \mathrm{He}(\mathrm{d}, \mathrm{p}){ }^{4} \mathrm{He}$ reaction. In a subsequent experiment in the low-energy region, $\mathrm{Kunz}^{19}$ disagrees with the above data. He had an energy shift from 5-15 keV higher, so his crosssection values are $30-50 \%$ lower than the previous work. Figures 9 and 10 show the comparison between Kunz's experiments and those of Bonner, Conner, and Lillie, ${ }^{18}$ Carlton, ${ }^{22}$ and Arnold et al. ${ }^{4}$

Note that Kunz normalizes his absolute scale by his measurements of the $D(t, n)$ reaction with his equipment

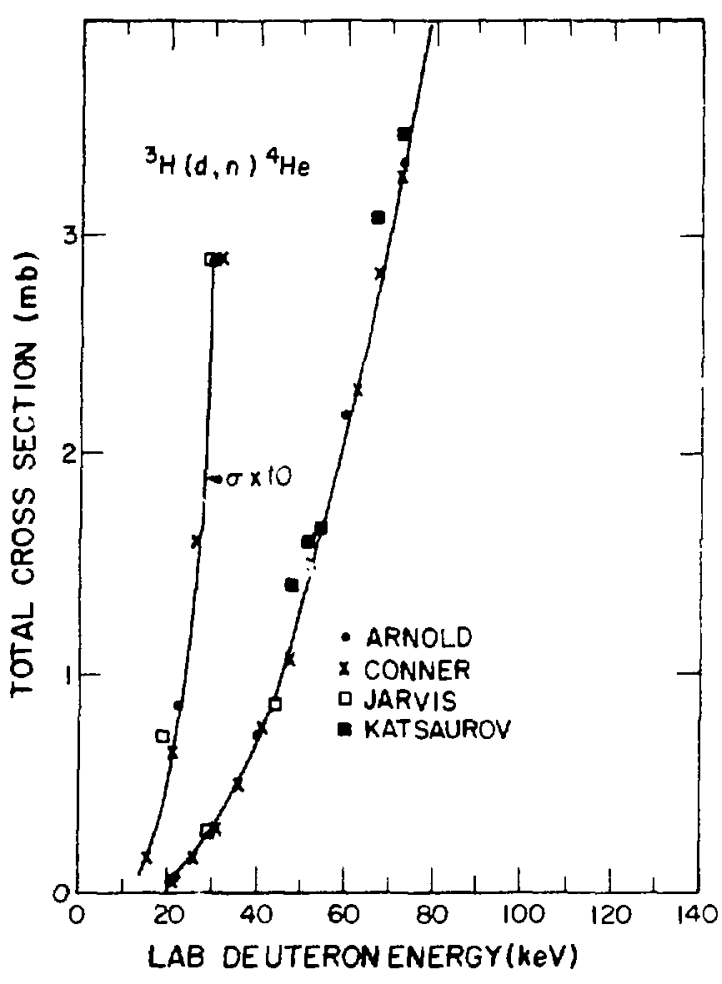

Fig. 8.

Low-energy detail of the $T(d, n)^{4} \mathrm{He}$ tolal crosssection data, again showing the energy shift of the Katsaurov data. ${ }^{6}$

and by normalizing to the peak value of the $T(d, n)$ measurement of Conner, Bonner, and Smith. ${ }^{3}$ His agreement with Bonner. Conner, and Lillie ${ }^{38}$ at the peak of the resonance is no surprise, but the disagreement at lower energies again indicates an energy measurement problem.

Detail of the low-energy ${ }^{3} \mathrm{He}(\mathrm{d}, \mathrm{p})$ reaction is given in Fig. 11. Again, Jarvis and Roaf" disagree with the Rice ${ }^{3}$ and LASL" experiments and agree with Kunz. ${ }^{19}$ Note that the apparent energy shift of the "standard" work is opposite that of the $T(d, n)$ case shown in Fig. 8.

An unpublished report of a measurement on the ${ }^{3} \mathrm{He}\left({ }^{3} \mathrm{He}, 2 \mathrm{p}\right){ }^{4} \mathrm{He}$ reaction was made in 1969 by Dwarakanath, ${ }^{23}$ in which he included a measurement of the ${ }^{3} \mathrm{He}(\mathrm{d}, \mathrm{p})^{4} \mathrm{He}$ total cross section. His data are not available in tabular form. Inspection of his graphical results indicates, paradoxically, that his data agree with Arnold et al. ${ }^{4}$ and Bonner, Conner, and Lillie ${ }^{18}$ at low energies. 


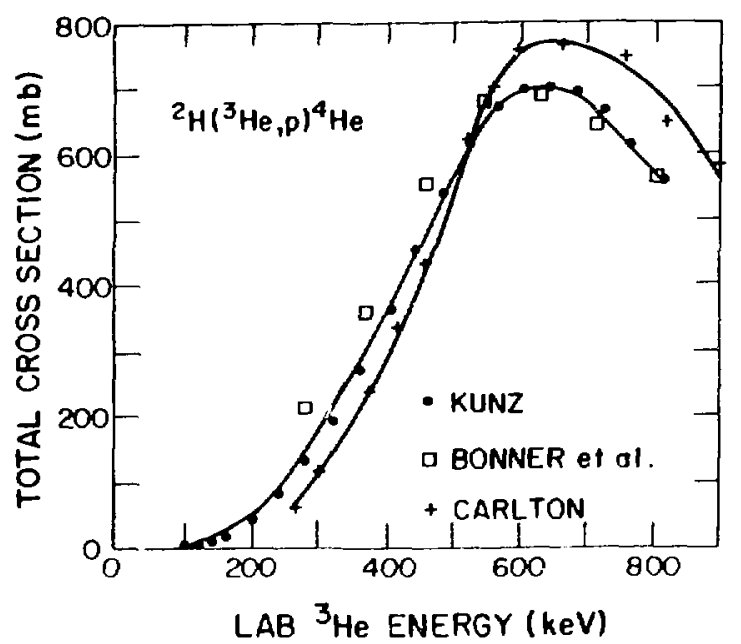

Fig. 9.

$D\left({ }^{3} \mathrm{He}, p\right)^{4} \mathrm{He}$ total cross section at higher energies. Note discrepancies in the absolute value of the peak and in data on the lower energy side where Bonner $^{18}$ and Carlton $^{22}$ disagree by 50-100\%.

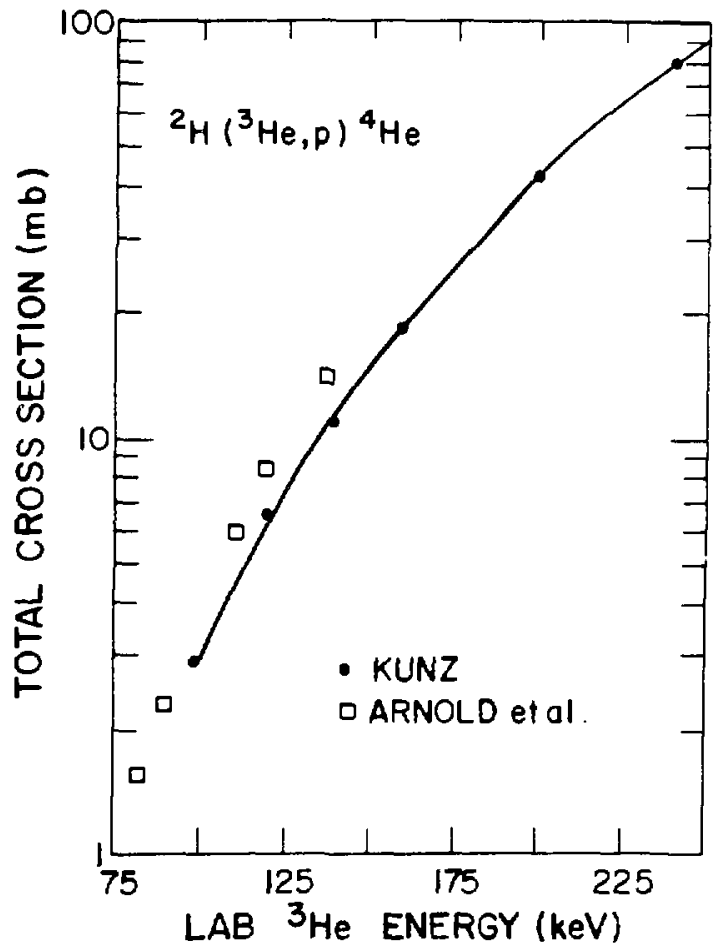

Fig. 10.

$D\left({ }^{3} \mathrm{He}, \mathrm{p}\right)^{4} \mathrm{He}$ total cross section at lower energies.

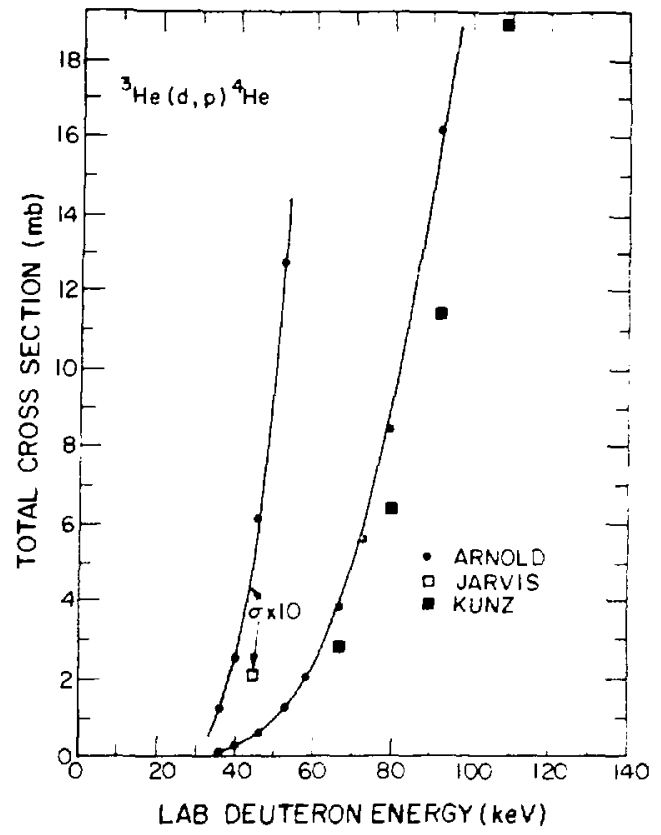

Fig. 11 .

Low-energy detail of the ${ }^{3} \mathrm{He}(d, p)^{4} \mathrm{He}$ total cross section. Compare with Fig. 8.

While not immediately germane to the low-energy energy shift question, it is of interest to note crosssection disagrcements at the resonance peak (at about $650 \mathrm{keV}$ in Fig. 9). In addition to the data shown, Yarnell $^{21}$ measures a peak value of $900 \mathrm{mb}$, whereas Freier and Holmgren ${ }^{20}$ and Dwarakanath ${ }^{23}$ measure about $940 \mathrm{mb}$. Alsi, the data of Kliucharev ${ }^{24}$ agree with those of Carlton. ${ }^{22}$ These remarkable differences (as much as $35 \%$ ) await a reliable experimental resolution. A summary of the peak discrepancy is given by Carlton. ${ }^{22}$ Because of lack of any discrimination criteria, Greene used the data from Refs. 5, 8, 18-21, as discrepant as they were.

The same accelerator and absolute energy measurement used in the Arnold et al. ${ }^{4} \mathrm{~T}(\mathrm{~d}, \mathrm{n})$ measurement were used by Phillips ${ }^{48}$ in the ${ }^{6} \mathrm{Li}\left(\mathrm{p},{ }^{3} \mathrm{He}\right)^{4} \mathrm{He}$ reaction. Figure 12, taken from the work of Elwyn et al. ${ }^{47}$ shows Phillips data to be high by a factor of 2 or 3 in the lowenergy region compared to the data of Fiedler and Kunze $^{49}$ and Gemeinhardt. ${ }^{30}$ it is not clear how much of this discrepancy is due to a possible energy shift. 


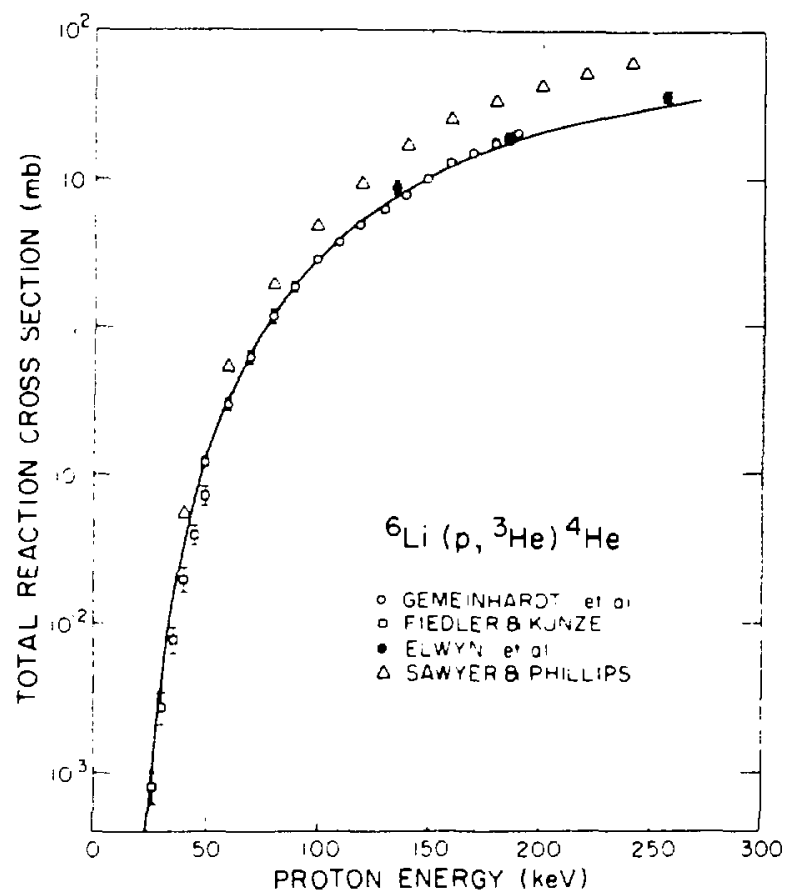

Fig. 12.

Total reaction ross section for the ${ }^{6} \mathrm{Li}\left(\mathrm{p},{ }^{3} \mathrm{He}\right)^{4} \mathrm{He}$ reaction. The data are from Gemeinhardt et al., ${ }^{30}$ Fiedler and Kunze, ${ }^{49}$ Elwyn et al., ${ }^{47}$ and Phillips..$^{48}$ The curve is an $R$-matrix extrapolation formula ${ }^{47}$ based on the data of Gemeinhardt. ${ }^{30}$

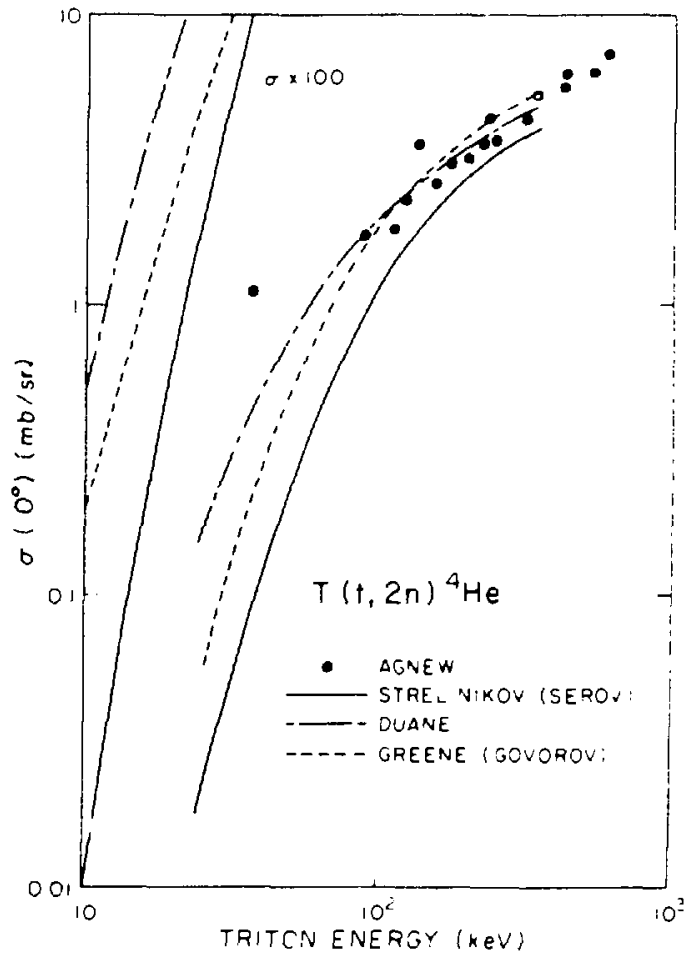

Fig. 13.

The $T(t, 2 n)^{4} \mathrm{He}$ zero-degree differential cross section is triton bombarding energy. Green's total cross section preaiction. ${ }^{10}$ based on Govorov, ${ }^{25}$ is divided by 10 to obtain the curve. Duane's prediction ${ }^{14}$ is based on the Agnew data ${ }^{26}$ The Serov data $^{29}$ closely follow the Strel'nikov data, ${ }^{21}$ represented by the solid line. 
discrepant appearance of Fig. 14, a linear plot of the total cross section $\sigma_{\mathbf{T}}$ at low energies. Except $f_{c}-$ the lowest energy data of Agnew ${ }^{26}$ and Govorov, ${ }^{25}$ there is no unusual disagreement. The line is an R-matrix fit up to $2 \mathrm{MeV}$ by Hale, Young, and Jarmie ${ }^{11}$ to the total cross-section data of Refs. 25, 29, and 34. The R-matrix solution leads to a prediction of the reactivity of the $\mathrm{T}(\mathrm{t}, 2 \mathrm{n})^{4} \mathrm{He}$ reaction about $50 \%$ smaller than that predicted by Greene, ${ }^{10}$ below $50 \mathrm{keV}$ bombarding energy. The data in this low-energy region are dominated by the work of Serov et al., who made a special effort to measure the bombarding energy accurately. Even if they were successful, their energy error is still 2 to 3 $\mathrm{keV}$, and the stated errors in their cross sections are from 20 to $30 \%$. Considering the other inconsistencies mentioned, our knowledge of $\mathrm{T}(t, 2 n)^{4} \mathrm{He}$ cross sections is not secure.

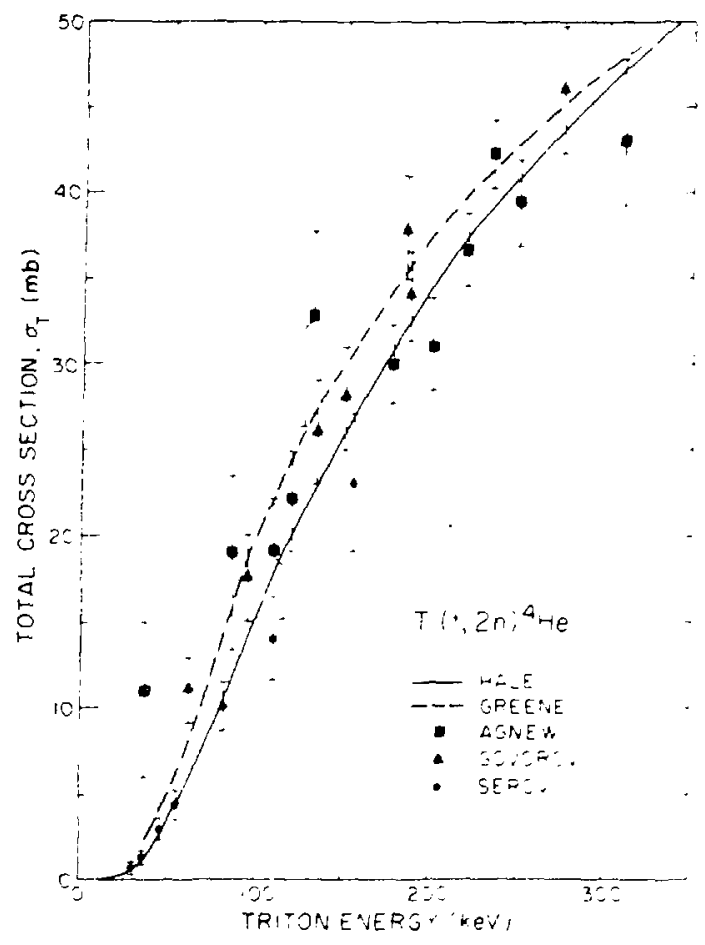

Fig. 14.

$T(t, 2 n)^{4} \mathrm{He}$ total cross section vs triton bombarding energy. Shown are the data of Agnew et al., ${ }^{26}$ Govorov, ${ }^{25}$ Serov, ${ }^{28}$ and the predictions of Greene $^{10}$ and Hale et al. ${ }^{13}$

\section{D. $D(d, p) T$ and $D(d, n)^{3} \mathrm{He}$.}

McNeill ${ }^{36}$ revised the total cross-section data of $\mathrm{Ar}$. nold et al. ${ }^{4}$ upward by $3 \cdot 12 \%$ io account for improved anisotropy measurements. With this improvement, the absolute experiments mentioned in Sec. II agree within experimental crrors. which are $\sim 10-15 \%$. except for Arnold. ${ }^{4}$ who quotes $2.5 \%$. Therefore, the data agreement for $d+d$ reactions is satisfactory. The $d+d$ data sets in various computer programs (which probably come from Arnold's data ${ }^{4}$ ) should be corrected for McNeill's anisotropy revision, although it may not make a significant difference in most fusion calculations at present.

Arnold et al. ${ }^{4}$ used the same apparatus for obtaining data in both $d+d$ and $T(d, n)$ experiments. The apparent agreement of Arnold's $d+d$ data with the other $d+d$ experiments adds another heuristic element in the question of the reliability of their $\mathrm{T}(\dot{d} . n)$ data.

\section{CONCLUSIONS}

In all but the $d+d$ reactions, there are significant differences among data sets. Clues point to the difficulty of making accurate low energy measurements.

1. Systematic errors up to $50 \%$ are possible in the reactivity values for the 10 - to $100-\mathrm{keV}$ deuteron energy region of the present $\mathrm{T}(\mathrm{d} . \mathrm{n})^{4} \mathrm{He}$ data base. most likely because of energy-scale errors in the experiments. The reactivity errors would propagate proportionately into the fusion probability errors in reactor calculations.

2. ${ }^{3} \mathrm{He}(\mathrm{d} . \mathrm{p})^{4} \mathrm{He}$ reaction cross sections could be in error by as much as $50 \%$ in the low-energy region.

3. The $\mathrm{D}(\mathrm{d} . n)^{3} \mathrm{He}$ and $\mathrm{D}(\mathrm{d} . \mathrm{p}) \mathrm{T}$ cross sections appear to be well known and consistent.

4. The $T(t .2 n)^{4} \mathrm{He}$ cross sections are not well known and may be subject to large systematic errors.

5. Improved absolute measurements in the 10- to 100 . $\mathrm{keV}$ bombardin energy region would be useful. Un. til such experiments are done, data sets for fusion reaction calculations should be left as they are lexcept for $T(t .2 n)^{4} \mathrm{He}$ data, which could be lowered by $\sim 50 \%$. Apparent uncertainties of the data sets should be kept in mind. 


\section{ACKNOWLEDGMENTS}

The private communication of data and written material from A. M. Govorov, A. J. Elwyn, and R. Santort are gratefully acknowledged. Discussions with $G$. M. Hale, L. Stewart, and R. Brown were also helpful.

\section{REFERENCES}

I. C. A. Barnes, "Nucleosynthesis by ChargedParticle Reactions," Adv. Nucl. Phys. 4, 133, p. 140 (1971).

2. F. L. Ribe, T. A. Oliphant, Jr., and W. E. Quinn, "Feasibility Study of a Pulsed Thermonuclear Reactor," Los Alamos Scientific Laboratory report LA-3294-MS (1965); and I. D. Lawson, "Some Criteria for a Power-Producing Thermonuclear Reactor," Proc. Phys. Soc. B70, 6 (1 1 557 ).

3. N. Jarmie and J. Wallace, "Low-Energy Nuclear Fusion Data and Their Relation to Nuclear Weapons Design," Los Alamos Scientific Laboratory report LA.7418 (1978).

4. W. R. Arnold, J. A. Phillips, G. A. Sawyer, E. J. Stovall, Jr., and J. L. Tuck, "Cross Sections for the Reactions $D(d, p) T, D(d, n) H^{3}, T(d, n) H^{4}$ and $\mathrm{He}^{3}(\mathrm{~d}, \mathrm{p}) \mathrm{He}^{4}$ Beiow $120 \mathrm{keV}$," Phys. Rev. 93, 483 (1954); see also by the same authors, "Absolute Cross Section for the Reactions $\mathrm{T}(\mathrm{d}, \mathrm{n}) \mathrm{He}^{4}$ from !s to $120 \mathrm{keV}$." Los Alamos Scientific Laboratory report LA-1479 (1953).

5. J. P. Conner, T. W. Bonner, and J. R. Smith, "A Study of the $\mathrm{H}^{3}(\mathrm{~d}, \mathrm{n}) \mathrm{He}^{4}$ Reactions," Phys. Rev. 88, 468 (1952).

6. L. N. Katsaurov, "Investigation of the Reaction $\mathrm{D}(\mathrm{T}, \mathrm{n})^{4} \mathrm{He}$ by the Thin-Target Method in the Energy Region from 40 to $750 \mathrm{keV}$," Akad. Nauk, USSR, Trudy, Fizicheskii Inst. 14, 224 (1962); and E. M. Balabanov, I. Ia. Barit, L. N. Katsaurov, I. M. Frank, and I. V. Shtranikh, "Measurement of the Effective Cross Section for the $D(t, n)^{4} \mathrm{He}$ Reaction in the Deuteron Energy Range $40.730 \mathrm{keV}$," Suppl. 5. Sov. J. At. Energy, Atomnaya Energiya, p. 43 (1957).
7. R. G. Jarvis and D. Roaf, "Comparison of D-T anu D ${ }^{3} \mathrm{He}$ at Low Energies," Proc. Roy. Soc. A218, 432 (1953).

8. R. L. Miller, Los A!amos Scientific Laboratory, private communication, 1977.

9. Fusion Forefront 10, No. 3, 7 (1977).

10. S. L. Greene, Jr., "Maxwell Averaged Cross Sections for Some Thermonuclear Reactions on Light 1sotopes," Lawrence Radiation Laboratory report UCRL 70522 (May 1967).

11. J. L. Tuck, "Thermonuclear Reaction Rates," Los Alamos Scien'fic Laboratory report LAMS-1640 (March 1954), revised 1961.

12. L. M. Hively, "Convenient Computational Forms for Maxwellian Reactivities." Nucl. Fusion 17 , 873 (1977).

13. G. H. Miley, H. Towner, and N. Jvich, "Fusion Cross Sections and Reactivities," University of II. linois report COO-2218-17 (1974).

14. B. H. Duane, "Fusion Cross Section Theory," in "Pacific Northwest Laboratory Report on Controlled Thermonuclear Reactor Technology-1972," W. C. Wolkenhauer, Ed., Battelle Northwest Laboratory report BNWL-1685 (November 1972) p. 75.

15. L. A. Artsimovich, "Controlled Thermonuclear Reactions," Russian: Fiz latgiz, Moscow, p. 7 (1961); Translation: Gordon and Breach, p. 2, New York (1964).

16. Erick L. Lindman, Los Alamos Scientific Laboratory, private communication, 1979.

17. L. Stewart and G. M. Hale, "The $T(d, n)^{4} \mathrm{He}$ and $T(t, 2 n)$ Cross Sections at Low Energies," Los Alamos Scientific Laboratory report LA-5828-MS (January 1975).

18. T. W. Bonner, J. P. Conner, and A. B. Lillie, "Cross-Section and Angular Distribution of the $\mathrm{He}^{3}(\mathrm{~d}, \mathrm{p}) \mathrm{He}^{4}$ Nuclear Reaction." Phys. Rev. 88, 473 (1952). 
19. W. E. Kunz, "Deuterium $+\mathrm{He}^{3}$ Reaction," Phy's. Rev. 97, 456 (1955).

20. G. Freier and H. Holmgren, "Interaction Between $\mathrm{D}^{2}$ and $\mathrm{He}^{3}$ in the Neighborhood of the $18.6 \mathrm{-MeV}$ Level of $\mathrm{Li}^{9 *}$." Phys. Rev. 93, 825 (1954).

21. J. L. Yarnell, R. H. Lovberg, and W. R. Stratton, "Angular Distribution of the Reaction $\mathrm{He}^{3}(\mathrm{~d}, \mathrm{p}) \mathrm{He}^{4}$ Between $240 \mathrm{keV}$ and $3.56 \mathrm{MeV}, "$ Phys. Rev. 90, 292 (1953).

22. R. F. Carlton, "A Determination of the Absolute Cross Section for the ${ }^{3} \mathrm{He}(d, p)^{4} \mathrm{He}$ Reaction," Thesis, University of Georgia (1970).

23. M. R. Dwarakanath, "Total Cross Section Measurements for ${ }^{3} \mathrm{He}\left({ }^{3} \mathrm{He}, 2 \mathrm{p}\right)^{4} \mathrm{He}$ at Low Energies," Thesis, California Institute of Technology (1969).

24. A. P, Kliucharev, B. N. Esel'son, and A. K. Val'ter, "A Study of the Reaction of $\mathrm{He}^{3}$ with Deuterons," Sov. Phys. Dokl. 1, 475 (1956).

25. A. M. Govorov, Li Ka-Yeng, G. M. Osetinskii, V. I. Salatskii, and 1. V. Sizor, "Total Cross Section of the $T+T$ Reaction in the 60-1140 keV Energy Range," Sov. Phys.JETP 15, 266 (1962).

26. H. M. Agnew, W. T. Leland, H. V. Argo, R. W. Crews. A. H. Hemmendinger, W. E. Scott, and R. $F$. Taschek, "Measurement of the Cross Section for the Reaction $\mathrm{T}+\mathrm{T}=\mathrm{He}^{4}+2 \mathrm{n}+11.4 \mathrm{MeV}$," Phys. Rev. 84, 862 (1951).

27. Yu. V. Strel'nikov, S. N. Abramovich, L. A. Morkin, N. D. Yur'eva, "Excitation Function for the Reaction ${ }^{3} \mathrm{H}(\mathrm{t}, 2 \mathrm{n})^{4} \mathrm{He}$ at $0^{\circ}$ Angle and Energies of 40-200 keV," Bull. Acad. Sci. USSR Phys. Ser. (Isvestia) 35, 149 (1971).

28. V. I. Serov, S. N. Abramovich, and L. A. Morkin, "Total Cross Section Measurement for the Reaction $\mathrm{T}(\mathrm{t}, 2 \mathrm{n})^{4} \mathrm{He}$," Sov. J. At. Energy 42, 66 (1977).

29. National Nuclear $r$ Data Center, Brookhaven National Laboratory Data Base CSISRS (EXFOR) \#A0007, 770825.
30. A. M. Govorov, Li Ha Youn. G. M. Osetinskii, V. I. Salatskii, and I. V. Sizov, "lotal Cross Section of the $T+T$ Reaction in the $60-1140 \mathrm{keV}$ Fncrgy Range," Sov. Phys.JETP 14, 508 (1962).

31. S. J. Bame. Jr.. and W. T. Leland, "Neutron Spectrum from T + T." Phys. Rev. 106, 1257 (1957).

32. C. Wong. J. D. Anderson, and J. W. McClure, "Niutron Specirum from the $T+T$ Reaction," Nucl. Phys. 71. 106 (1965).

33. R. Larose-Poutisscu and $H$. Jeremie. "The ${ }^{3} \mathrm{H}(\mathrm{t}, \alpha) 2 \mathrm{n}$ Reaction at $40 \mathrm{keV}, "$ Nucl. Phys. A218, 559 (1974).

34. N. Jarmie and R. C. Allen, "T(t, $\alpha) n, n$ Reaction," Phys. Rev. 111, 1121 (1958).

35. R. B. Theus, W. 1. McGarry, and L. A. Beach, "Angular Distributions and Cross-Section Ratios for the Reactions ${ }^{2} \mathrm{H}(\mathrm{d}, n)^{3} \mathrm{He}$ and ${ }^{2} \mathrm{H}(\mathrm{d}, \mathrm{p})^{3} \mathrm{He}$ below 500 keV." Nucl. Phys. 80, 273 (1966).

36. K. G. McNeill and G. M. Keyser, "The Relative Probabilities and Absolute Cross Sections of the D. D Reactions," Phys. Rev. 81, 602 (1951).

37. W. A. Wenzel and W. Whaling. "Cross Section and Angular Distribution of the $\mathrm{D}(\mathrm{d}, \mathrm{p}) \mathrm{T}$ Reactions," Phys. Rcv. 88. 1149 (1952).

38. P. A. Davenport. T. O. Jeffries. M. E. Owen, F. V. Price, and D. Roaf, "The D-D Cross-Section and Angular Distribution Between 55 and $430 \mathrm{keV."}$ Proc. Roy. Soc. A216. 66 (1953).

39. E. A. Eliot. D. Roaf, and P. F. D. Shaw, "The Cross Section and Angular Distribution of the D-D Reactions below $50 \mathrm{keV}, "$ Proc. Roy. Soc. A216, 57 (1953).

40. G. Preston, P. F. D. Shaw, and S. A. Young, "The Cross-Section and Angular Distribution of the D-D Reactions Between 150 and $450 \mathrm{keV}$." Proc. Roy. Soc. A226. 206 (1954). 
41. D. Magnar-Valette, E. LaCombe, R. Bilwes, and P. Cuer. "Determination Des Sections Efficaces De La Reaction $\mathrm{D}+\mathrm{D}=\mathrm{p}+\mathrm{T}+4,03$ A Des Energies Inferieures A $15 \mathrm{keV}, "$ J. Phys. Radium 24. 125 (1960).

42. A. von Engel and C. C. Goodyear, "Fusion CrossSection Measurements with Deuterons of Low Eñeıgy," Proc. Roy. Soc. A264, 445 (1961).

43. K. G. McNeill, "A Note on the Branching Rate of the D-D Reactions," Phil. Mag. 46, 800 (1955).

44. V. A. Davidenko, A. M. Kucher, 1. S. Pogrebov, and Iu. F. Tuturov, "Nuclear Reactions in Light Nuclei," Suppl. 5, Sov. J. At. Energy, Atomnaya Energiya, p. 7 (1957).

45. A. S. Ganeev, A. M. Govorov, G. M. Osetinskii, A. N. Rakivienko, I. V. Sizov, ard V. S. Siksin, "The D.D Reaction in the Deuteron Energy Range 100$1000 \mathrm{keV}, "$ Suppl. 5, Sov, J. At. Energy, Atc.mnaya Energiya, p. 21 (1957).

46. R. Saritoro and J. Barish, "Cross Section Sensitivity of the D.T Fusion Probability and the D.T and T-T Reaction Rates." Nucl. Sci. and Engineering 59, 189 (1976) and Oak Ridge National Laboratory report ORNL-TM-4933 (1976) (contents of the articles differ).

47. A. J. Elwyn, R. E. Holland, C. N. Davids, L. Meyer-Schutzmeister, and F. P. Mooring; "Cross Sections for ${ }^{6} \mathrm{Li}\left(p,{ }^{3} \mathrm{He}\right)^{4} \mathrm{He}$ at Energies Between 0.1 and $3 \mathrm{MeV}, "$ Phys. Rev. C20, 1984 (1979); see also Bull. Am. Pl ys. Soc. 23, 97 (1978).

48. J. A. Phillips, "Survey of Several of the Reactions Occurring when Lithium and Beryllium are Bombarded by Protons and Deuterons of $30.250 \mathrm{keV}, "$ Los Alamos Scientific Labcratory report LA 1578 (1953).

49. O. Fiedler and P. Kunze, "Wirkungsquerschnitte der Kernreaktionen ${ }^{6} \mathrm{Li}(\mathrm{p}, \alpha)^{3} \mathrm{He}$ and ${ }^{7} ! \cdot(\mathrm{i}, \alpha)^{4} \mathrm{He}$ bei Kleinsten Energien," Nucl. Phys. A96, 513 (1967).

50. W. Gemeinhardt, D. Kamke, and Chr. von Rhoneck, "Ninkelverteilung und W'irkungs querschnitt det Reaktion ${ }^{6} \mathrm{Li}(\mathrm{p}, \alpha)^{3} \mathrm{He}$ im Erergiebereich von 50 vis $190 \mathrm{keV}, "$ Zeit. fur Physik 197. 58 (1966).

51. G. M. Hale, P. G. Young, and N. Jarmie, Los Alamos Scientific Laboratory, private communica tion, 1979. 